\title{
Getting Great Recommendation Letters: A Practical Guide
}

\section{Dr. Katy Luchini-Colbry, Michigan State University}

Katy Luchini-Colbry is the Director for Graduate Initiatives at the College of Engineering at Michigan State University, where she completed degrees in political theory and computer science. A recipient of a NSF Graduate Research Fellowship, she earned Ph.D. and M.S.E. in computer science and engineering from the University of Michigan. She has published more than two dozen peer-reviewed works related to her interests in educational technology and enhancing undergraduate education through handson learning. Luchini-Colbry is also the Director of the Engineering Futures Program of Tau Beta Pi, the Engineering Honor Society, which provides interactive seminars on interpersonal communications and problem solving skills for engineering students across the U.S. 


\title{
Getting Great Recommendation Letters: A Practical Guide
}

\begin{abstract}
This paper describes the role and value of recommendation letters in academic contexts, such as a graduate school or fellowship application, and provides specific advice for getting recommendation letters that will enhance and support such applications. Specific strategies are offered for deciding who to ask for recommendations, and detailed advice is given on how to prepare background information that will assist letter writers in highlighting the range of applicants' skills and abilities.
\end{abstract}

\section{Introduction}

Recommendation letters are typically one component of a larger application package, which may also include transcripts, test scores, statements of purpose, and a resume. Before asking for recommendation letters, you should consider the purpose and scope of the opportunity, and determine what types of recommendations would be most appropriate and helpful in convincing the reviewer that you are the best fit for this opportunity.

For instance, typical graduate school applications require the following elements:

- Statement(s) of Purpose: an opportunity for you to explain your preparation for graduate study and how you "fit" with the goals and opportunities of the institution to which you are applying

- Resume/CV: an opportunity for you to describe research, work and volunteer experiences, as well as honors, publications, etc.

- Transcripts and Test Scores: a detailed summary of your academic performance and potential

- Recommendations: typically 3 letters, at least 2 of which should come from faculty

You should think strategically about your recommendation letters, and how they can be used to highlight your strengths and fill in any "gaps" that may not be covered by your resume or transcripts. Some positive elements that you may want to have highlighted in your application materials and/or recommendation letters include:

- Research experience (volunteer or paid work in a lab; independent study with a faculty; extensive research or design projects completed as part of coursework; research or problem solving skills developed through internships or work experience)

- Industry experience (volunteer or paid internships; opportunities to solve problems, test equipment, investigate materials, give presentations, work in a team, etc.)

- Leadership experience (serving as an officer in student organizations; organizing an event or activity; leading a research or project team, etc.) 
- Teamwork skills (working effectively with others to solve problems or complete projects; leading a team; solving interpersonal problems; effective communications, etc.)

- Communication skills (giving oral presentations; developing written reports or materials; generating web content, blogs, or social media posts; interpersonal communications, etc.)

Of course, it is also essential to think carefully about the purpose of the recommendation (graduate school applications, fellowship nominations, jobs, etc.) and select recommenders who can speak about the applicant's preparation for the specific opportunity.

\section{Choosing Recommenders}

Ideally, you will ask for recommendation letters from individuals who both know you well and can write effectively [1]. Faculty, advisers, internship/work supervisors, coaches and individuals who have supervised your volunteer or extracurricular activities can all make good choices.

Faculty are used to having students ask them for recommendations, and are generally happy to assist. However, a generic recommendation letter from someone who does not know you well may do more harm than good - in this case, "faint praise" [2] from a faculty who can only say that you attended class and earned a 4.0 is not particularly valuable, while a graduate student with whom you've spent months conducting research may be able to write a strong, detailed letter that is highly valuable, even though the writer does not (yet) have a PhD. Generally, it is not appropriate to ask family members or very close friends to provide recommendations; however, the following may be excellent sources of recommendation letters:

- Faculty who have been your teachers

- Faculty, post-docs or graduate students who have supervised your research

- Faculty or advisers who have supervised your leadership or volunteer activities

- Supervisors from your professional internships and jobs

- Community leaders whom you have worked with on outreach or volunteer activities

In considering whether a particular recommender can write an effective letter, consider the following criteria (adapted from [3]):

- Is the recommender aware of your field of interest and the schools/jobs/programs you are applying to?

- Is the recommender able to evaluate your performance in your field of interest?

- Is the recommender able to discuss your personal characteristics?

- Is the recommender able to discuss your capacity to work with others?

- Can the recommender discuss your leadership skills?

- Can the recommender evaluate your level of professionalism (e.g., punctuality, efficiency, assertiveness)?

- Can the recommender discuss your academic skills -- not simply experience, but evaluate your potential to succeed in graduate-level study or the workplace?

- Does the recommender evaluate you positively relative to others of similar capabilities (i.e., how does the recommender rate you in comparison to your peers)? 
- Is the recommender a recognized expert in the field, and is the recommender's judgment highly valued within the field?

- Is the recommender able to write a good reference letter (i.e., literate, coherent, topical)

While an individual recommender may not meet all of these criteria, someone who meets few or no items on this list may not be the most effective recommender for you.

\section{How to Ask for a Recommendation}

When you ask for a recommendation, ask specifically: "Would you be comfortable writing me a strong letter of recommendation?"[4]. While most faculty and supervisors will agree to provide a letter, if you specifically ask for a strong recommendation then you may hear back that some individuals do not feel they could write you the strongest possible letter for this particular opportunity. This is not necessarily a reflection on you and your abilities - often the potential recommender is just acknowledging that they don't know you or your abilities well enough to provide a strong letter of support, or that they don't have sufficient time or skill to develop the strongest possible letter for you. If the person you ask for a recommendation declines, you should thank them for their consideration.

If the person you ask for a recommendation agrees to provide a letter, you should thank them and follow up with written details about what is required for the letter (deadline, submission instructions, content, etc.). You should also include a brief description of what you are applying for, drafts of any application materials, and your current resume or CV. Ask for recommendations at least 3-6 weeks in advance of the deadline; asking earlier than that is okay, but you should also follow up closer to the deadline.

In order to make sure that your recommendation letters complement your other application materials, it is wise to ask each recommender to highlight specific aspects of their interactions with you. For instance, you might ask your research mentor to emphasize your experiences in the lab, ask another faculty mentor to talk about your academic abilities, and ask the faculty adviser from your student professional society to talk about your leadership skills and outreach activities.

Often, it is helpful to provide a few bullet points for each recommender, reminding him/her of key experiences, dates, and details that may be appropriate for the recommendation letter. However, do not provide exactly the same language to each recommender. It is fairly common for recommenders to take language from your bullet points and integrate it into their letter, and you do not want all of the recommendations to use identical language.

\section{Examples}

The specific information you provide to your recommenders will depend on what you want them to emphasize in their letter, and what they know about you; the following examples outline some common types of information that may be helpful for you to provide to various recommenders; you can find additional ideas at [5]. 
Relationship and Roles: how and when did you meet the recommender? What were your respective roles? What projects, classes, etc., did you work on? Examples of how to describe this information in bullet points include:

- I met you in Fall 2016 when I enrolled in your computer programming course; I came to your office hours to talk about a project and ended up volunteering in your lab to work on educational interface design.

- After volunteering for two semesters, you hired me to work in the lab full-time in Summer 2017. I worked on a project studying ways to integrate scaffolding into educational software for middle school science students.

- You introduced me to Dr. Smith in 2016 and encouraged me to pursue a research project in her lab this year, focusing on handheld interfaces.

Academic Abilities: what information does the recommender have to assess your academic potential? Include coursework, special projects, honors, etc., as appropriate. For example:

- I am a member of the university's honors program and worked with you on projects in Engineering 100 and 101 during 2016-17.

- I am pursuing a bachelor's degree in mechanical engineering with a minor in Spanish, and have earned a 3.6 / 4.0 cumulative GPA; I've been on the Dean's list every semester since 2015.

- I won a merit-based scholarship to attend the ASEE National Conference and present my undergraduate research project, and I was named the top undergraduate in my major during my junior year.

Professional Experience: how have you demonstrated competency and excellence in a professional setting? What projects did you work on? What training did you complete? What were the outcomes of your work? For instance:

- I interned with the product development team during summer 2016.

- I was asked to update the testing manual for the new product line, to be released in early 2018, and generated over 5,000 test cases during the three month summer internship.

- I completed eight hours of training in professional ethics and standards as part of the internship program, and participated in a day-long seminar on advanced manufacturing techniques.

Research Experience: consider both paid and volunteer experiences, as well as substantial research projects completed as part of your technical coursework. Include descriptions of the project and your role and describe the research skills you developed, specialized software or equipment you used, and how your work contributed to a larger research project. For instance:

- I began working in the research lab in Fall 2015, when I completed an independent study with Dr. Jones. My role was to collect and analyze user data using Excel and SPSS.

- After learning how to gather and analyze statistical information about users' interactions with the software, I developed a new study of two interface alternatives, which were tested in Summer 2016. 
- I presented my research as a poster at the 2016 Summer Undergraduate Research Forum, and contributed to a paper that was presented at ASEE 2017.

Teaching Experience: what were your responsibilities? What class(es) did you assist with? How many students did you work with, and who was your faculty supervisor? How did you demonstrate leadership and effective communications? Examples include:

- I was a teaching assistant for Engineering 101 during my senior year, working with a graduate student instructor and assisting in three sections of 20 student each week.

- I assisted in grading bi-weekly exams and projects, and provided support in the help room 5 hours per week.

- I developed a new supplemental module on Excel for use in the help room, and gave an in-class lecture on using Excel for tracking business expenses.

Outreach and Service: emphasize STEM (science, technology, engineering, math) outreach programs or activities you have participated in, describing the audience (e.g,. K-12 students, high school teachers) and activity. For example:

- As part of the executive board of SWE (Society of Women Engineers), I helped to organize weekly outreach activities with students at a local middle school. I coordinated the efforts of about 10 college students, who volunteered as math and science tutors for about 30 middle school students each week.

- During my senior year, I was elected president of our ASEE student division and had the opportunity to represent my university at the national conference. I also arranged a retreat for the executive board to build teamwork and communications skills, and secured funding from a corporate sponsor for this event.

\section{Following Up}

As the deadline approaches, be sure to follow up with your recommenders to make sure that they have the information that they need to submit their recommendations on time. Ask them to confirm with you once they have submitted the information, so that you can finalize your application materials. Be certain to send a thank you note or email after they have submitted a recommendation on your behalf - and make a note in your calendar to follow up with them after you have heard back about the opportunity for which they recommended you and let them know what happened. That provides a good opportunity for you to reconnect with your recommenders and maintain the relationship - which is beneficial if you need additional recommendations in the future.

\section{References}

[1] "How to Get a Recommendation Letter," About.com Graduate School. [Online]. Available: http://gradschool.about.com/od/askingforletters/ht/howletter.htm. [Accessed: 21-Oct-2012]. 
[2] R. M. Reis, "Getting Great Letters of Recommendation," The Chronicle of Higher Education, 02-Feb-2001.

[3] "Recommendation Letters: Choosing Referees," About.com Graduate School. [Online]. Available: http://gradschool.about.com/od/askingforletters/a/askrec.htm. [Accessed: 21-Oct2012].

[4] M. Might, "Asking for a letter of recommendation.” [Online]. Available:

http://matt.might.net/articles/how-to-recommendation-letter/. [Accessed: 21-Oct-2012].

[5] M. D. Jackson, "How to Get the Best Recommendation Letters for Grad School Article GradSchools.com." [Online]. Available: http://www.gradschools.com/article-detail/gettingrecommendations-116. [Accessed: 21-Oct-2012]. 